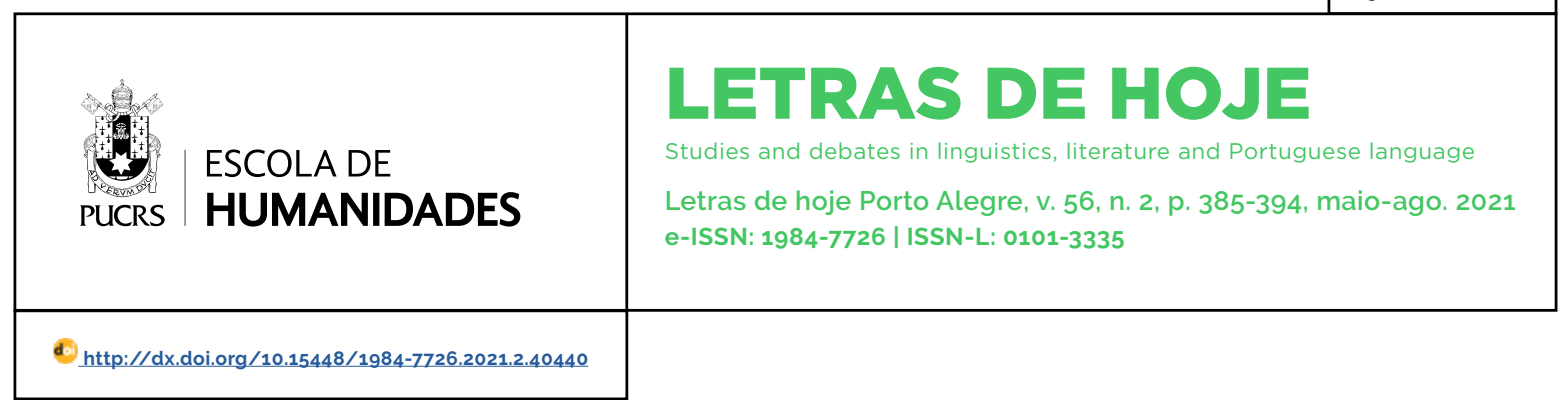

SEÇÃO: SEÇÃO LIVRE

\title{
Dois poemas da concreta Maria do Carmo Ferreira
}

\author{
Two poems by the concrete poet Maria do Carmo Ferreira \\ Dos poemas de la concreta Maria do Carmo Ferreira
}

\section{Monalisa Medrado \\ Bomfim $^{1}$}

orcid.org/0000-0002-1892-6085 monabomfim@gmail.com

Recebido em: 22 mar. 2021. Aprovado em: 3 jun. 2021. Publicado em: 9 nov. 2021.

\section{(c) (i)}

Artigo está licenciado sob forma de uma licença Creative Commons Atribuição 4.0 Internacional.
Resumo: O presente trabalho analisou dois poemas de Maria do Carmo Ferreira: "As parcas" e "De mim pra mins", com o objetivo de fornecer à poeta o reconhecimento histórico que cabe a ela, ao lado dos concretos, como alguém que não deixa a dever nem em referências poéticas, tampouco em articulação crítica. Para isso, levantou-se o fato de a poeta já ter publicado junto aos concretos na revista Invenção 5 e admitiu-se que a sua criação poética continua carregada de aspectos caros à poesia concreta. Para demonstrar que a poeta tinha consciência dos cercos que a invisibilizaram e que era por meio de sua poética que buscava transcendê-los, os poemas foram lidos à luz dos textos da Mistica feminina, de Betty Friedan, que busca delinear o que é o feminino e como ele é perigoso para as mulheres. Assim, se Maria do Carmo pretendeu comer o mundo com seus poemas, aqui, dar-se-á garfo e faca a ela.

Palavras-chave: Poesia concreta brasileira. Maria do Carmo Ferreira. Cercos invisiveis. Mistica feminina.

Abstract: The present work analyzed two poems by Maria do Carmo Ferreira: As parcas and De mim pra mins, aiming to give the poet the historical recognition that belongs to her, besides the concrete poets, as someone who leaves nothing to be desired neither in poetic references nor in critical articulation. In order to do so, the fact that she has already published with the concrete poets in the magazine Invenção 5 was raised and it was admitted that her poetic creation remains loaded with aspects dear to concrete poetry. In order to demonstrate that the poet was aware of the fences that made her invisible and that it was through her poetics that she sought to transcend them, the poems were read in the light of the texts of The Feminine Mystique, by Betty Friedan, which seeks to delineate what is the feminine and how dangerous it is for women. Thus, if Maria do Carmo intended to eat the world with her poems, here, she will be given a fork and knife. Keywords: Brazilian concrete poetry. Maria do Carmo Ferreira. Invisible fences. Feminine mystique.

Resumen: El presente trabajo analiza dos poemas de Maria do Carmo Ferreira: As parcas y De mim pra mins, con el objetivo de dotar a la poeta del reconocimiento histórico que le pertenece, junto a los concretos, como alguien que no deberia ni en referencias poéticas, ni en la articulación crítica. Tiendo en la mente que la poeta ya había publicado con los concretos en la revista Invenção 5 y se admitiendo que su creación poética queda cargada de aspectos queridos por la poesia concreta, cuesto trabajo ha demostrado que la poeta era consciente de los asedios que la hacian invisible y que era a través de su poética que buscaba trascenderlos. Por eso, los poemas fueron leidos a la luz de los textos de la Mistica femenina, de Betty Friedan, que busca delinear qué es lo femenino y qué tan peligroso es para las mujeres. Así, si Maria do Carmo pretendía comer el mundo con sus poemas, aquí le darán tenedor y cuchillo.

Palavras-clave: Poesía concreta brasileña. Maria do Carmo Ferreira. Asedios invisibles. Mistica femenina. 
"O fantasma era uma mulher, e quando a conheci meLhor, dei a ela o nome da heroina de um famoso poema, "O Anjo do Lar". Era ela que costumava aparecer entre mim e o papel enquanto eu fazia as resenhas. Era ela que me incomodava, tomava meu tempo e me atormentava tanto que no fim matei essa mulher".

(Virginia Woolf)

O encontro entre os irmãos Augusto e Haroldo de Campos com Décio Pignatari na Faculdade de Direito do Largo de São Francisco não poderia ser mais proveitoso para a história da literatura brasileira, pois fundam o que se conhece por poesia concreta. O trio começa publicando em 1949 na Revista Novíssimos, mas logo percebe-se em dissonância com o grupo e, em 1952, lançam a Revista Noigandres, que trazia poemas que rompiam com o tipo de produção dos Novíssimos. Segundo o crítico Gonzalo Aguilar (2005, p. 89), "até o início dos anos 1960, a produção do grupo concreto distribuía-se em diversos meios: os poemas em Noigandres, os ensaios em O Estado de São Paulo e no Jornal do Brasil e os manifestos em ad - arquitetura \& decoração".

A última edição da Noigandres foi publicada em 1962, se por um lado a revista delineou os tons da poesia concreta brasileira, por outro ela não podia "reunir e articular a produção do grupo em sua totalidade", como observa Aguilar (2005, p, 89). Assim, no mesmo ano, foi publicado o primeiro número da revista Invenção, que projetava "um organismo editorial autônomo e com as pretensões próprias de uma revista (diversidade de materiais, homogeneidade de design e formato, periodicidade e participação nos debates conjunturais)" (AGUILAR, 2005, p. 89). A equipe (então formada por Augusto de Campos, Cassiano Ricardo, Décio Pignatari, Edgar Braga, Haroldo de Campos, José Lino Grünewald, Mário Chamie, Pedro Xisto e outros poetas colaboradores) publicou cinco números da revista Invenção entre o primeiro trimestre de 1962 e janeiro de 1967.
No último número da Invenção, cercada por esse mar de homens, que nesta edição incluia, ainda, Erthos Albino de Souza e Luiz Angelo Pinto, localiza-se Maria do Carmo Ferreira, que contribui com o poema Meretrilho, já previamente analisado pelo pesquisador Felipe Martins Paros (2019). No poema, o crítico observa recursos estéticos de James Joyce, Mallarm, Apollonaire, e.e. cummings e João Cabral de Mello Neto, considerando que "sua ousadia maior foi flertar com o paideuma ${ }^{2}$ concreto" (PAROS, 2019, p. 40). Para além do flerte, sugere-se aqui que Maria do Carmo Ferreira caminhava ao lado dos concretos, como igual em termos de paideuma. Em entrevista à Suplemento Literário de Minas Gerais, por exemplo, a mineira demonstra que sua atividade tradutória não deixa a dever em comparação com os demais poetas considerados concretos. Nas palavras dela:

Tenho traduzido sistematicamente Emily Dickinson (uns 50 poemas), Neruda, Lorca, Prèvet e mais esparsamente Mallarmé, Verlaine, Corière, Laforgue, Yeats, e algumas poetas norte-americanas de minha preferência (FERREIRA, 2013, p. 13)

É importante lembrar que, a tradução era operada pelos concretos como um processo consciente com "sentido crítico e didático no contexto do movimento" (2006, p. 239), conforme assinala a biografia do grupo "noigandres". Ainda que tivessem inaugurado uma nova poesia, mesmo entre o trio fundador existiam diferenças no estilo, Augusto de Campos autodenomina-se "poetamenos" (2006, p. 29) e distingue Pignatari como "clown-sacerdote", já Haroldo de Campos "é, por assim dizer, um 'concreto' barroco" (2006, p. 57). Dessa forma, é possivel depreender que Maria do Carmo é concreta ao seu próprio estilo, que parece coincidir com algo de Joyce e Mallarmé. Nesse ponto, dar-se um passo atrás para pensar o poema concreto:

Os poemas concretos caracterizar-se-iam por uma estruturação ótica-sonora irreversivel e

\footnotetext{
2 Empresta-se a descrição de paiudema adotada por Haroldo de Campos no ensaio "Olho por olho a olho nu" (2006, p. 74): "PAIDEUMA elenco do autores cultumorfologicamente atuantes no momento histórico = evolução qualitativa da expressão poética e suas táticas: POUND - método ideogrâmico / léxico de essências e medulas (definição precisa) / JOYCE - método de palimpsesto / atomização da linguagem (palavra-metáfora) / CUMMINGS - método de pulverização fonética / (sintaxe espacial axiada no fonema) / MALLARMÉ método prismogrático (sintaxe espacial axiada nas "subdivisões prismáticas da ideia)".
} 
funcional e, por assim dizer, geradora da ideia, criando uma entidade todo-dinâmica 'verbivovovisual' - é o termo de Joyce - de palavras dúcteis, mondáveis, amalgáveis, à disposição do poema (CAMPOS, A. 2006, p. 56).

Verbivocovisual e palavra-metáfora são recursos joyceanos que ecoam em toda a produção poética de Maria do Carmo Ferreira, mesmo naquelas muito posteriores ao encerramento da experiência concreta, após a última publicação da revista Invenção. Como os demais, ela continua publicando, porém menos em livros ${ }^{3}$ e mais em revistas, como a Suplemento Literário de Minas Gerais, a Ímã, a Germina: revista de literatura \& arte e a Chicos, para citar apenas algumas. Aliás, o próprio Pignatari, ${ }^{4}$ revela um absoluto interesse na produção da poeta: "sempre gostei de seus poemas e fiquei esperando mais. Quando surgia um novo poema de Maria do Carmo, eu me interessava. [...] Ela tem um jeito moderno, forte e agressivo" (2000 apud FERREIRA, 2013, p. 31).

Paideuma definido, atividade de tradução sistemática e audácia pungente, Maria do Carmo parece caber perfeitamente no perfil de uma poeta que foi concreta enquanto a vanguarda fervia entre os intelectuais. Com isso em mente, admite-se que, como de costume, traços e tons da poesia concreta continuaram reverberando na sua produção poética, como pode ser visto nos poemas "As parcas" (1992) e "De mim para mins" (2003), analisados mais adiante. Antes disso, é interessante meditar que, se Maria do Carmo era tão concreta quanto os demais poetas, então, por que não ouvimos falar dela nos estudos críticos da área? Nesse ponto, abre-se um espaço para discutir o contexto da década de 1960 (que engloba o período de publicações da Invenção), isso porque, nem de longe ele era receptivo às mulheres e isso precisa ser considerado.

A artista plástica ítalo-brasileira Anna Maria Maiolino (2015), em recente entrevista, dá seu relato sobre ser mulher no periodo em questão. Mesmo casada com o também artista plástico Rubens Gerchman, Maiolino sente-se deixada de lado quando o assunto era promover a sua produção artística, nas palavras dela:

\begin{abstract}
Eu quero dizer essas coisas, porque há aqui uma questão do feminino, que para mim... não que eu seja feminista de chuteira, não é por aí, mas eu acho que a gente tem uma responsabilidade com gênero e minoria, entende? Eu estava em Nova York, já tinha participado dessas exposições, estava o Hélio Oiticica hospedado no loft, estava Amilcar de Castro, estava Ivan Freitas, e foi feito uma reportagem sobre artistas brasileiros na cidade. O que sobrou para Anna Maria Maiolino? Oferecer cafezinho. Nenhum desses homens me chamaram, nem meu próprio marido, para participar da reportagem. É duro, é muito duro! Por isso que eu digo que eu queria comer o mundo a mordida, porque estava furiosa, porque não tinha tempo para os meus sonhos (MAOIOLINO, [2015]). ${ }^{5}$
\end{abstract}

Com tantos membros homens na composição do grupo concreto, não é difícil imaginar que a situação narrada por Maiolino era corriqueira também no ambiente da poesia concreta. Por mais que sejam agressivas e ousadas, que queiram "comer o mundo a mordida", as mulheres estão cercadas por algo invisivel, algo como um "confinamento simbólico", para usar o termo do teórico Pierre Bourdieu (2012, p. 41). Esses cercos se apresentam nos hábitos fundamentais da sociedade e operam, no caso das mulheres, delineando o exato espaço que podem ocupar e a moral que devem exercer. A ativista Betty Friedan apelida essa disciplina forçada de mistica feminina, isto é, a incessante adaptação da mulher à figura "frivola, jovem, quase infantil; fofa e feminina; passiva, satisfeita num universo constituido de quarto, cozinha, sexo e bebés" (FRIEDAN, 1971, p. 34). No cenário de conto de fadas místico não há espaço para trabalho e divulgação artística ou literária, cabe à mulher o papel da anfitriã bela e atenciosa, que serve o cafezinho.

\footnotetext{
3 Ainda na entrevista à Suplemento Literário de Minas Gerais (2013, p. 31), Maria do Carmo indicou a publicações de pelo menos seis livros: "Estou com um livro de 125 poemas para sair já: Cave Carmen, um de traduções e quatro livrinhos infantis também inéditos: A flor que sofria de pensamento; O sacristão e a miss; Jogos florais \& animais e O Delfim que não sabia morrer".

4 O trecho da fala de Décio Pignatari foi publicado a primeira vez na Suplemento Literário de Minas Gerais 57 (2000), contudo, na impossibilidade de consultar esse número, o trecho foi retirado da parte introdutória do texto "Carmina Bu(saga)rana", publicado na Suplemento Literário de Minas Gerais (2013).

5 Trecho transcrito da entrevista fornecida ao Sesc TV (2015). Disponivel em: https://www.youtube.com/watch?V=4ZJ1bF1p8Yk. Acesso em: 21 jan. 2021.
} 
A questão, portanto, não é se Maria do Carmo estava ou não entre os concretos, pois ela definitivamente estava e produzia, mas sim onde a crítica a coloca quando reconta a história da poesia concreta brasileira e o problema é que não a mencionam. Nesse sentido, é possivel sugerir que, além do cerco ser invisivel, ele também invisibiliza. Empresta-se as palavras da feminista Adrienne Rich para frisar que a experiência de negligência experimentada pelas mulheres é real e naturalizada nos comportamentos sociais, não se concretizando apenas em um caso isolado, mas sim de maneira generalizada. Para Rich,

Tanto a vitimização quanto a raiva experimentada pelas mulheres são reais e têm fontes reais em todos os lugares dos ambientes construidos socialmente. Eles devem continuar sendo aproveitados e explorados por poetas, entre outros. Não podemos negá-los, nem os deixa descansar. Eles são nossas dores do parto e nós os estamos suportando em nós mesmas. Nós, estariamos falhando uma com as outras, como escritoras e como mulheres, se negligenciássemos ou negássemos o que é negativo [...]. Todos nós sabemos que há outra história a ser contada (RICH, 1972, p. 25, tradução nossa). ${ }^{6}$

\section{A ativista reforça a atenção para os cercos que} tolhem e invisibilizam as mulheres, pois, se existe a ilusão de que o patriarcado não é mais opressivo às mulheres, é preciso desmascará-la, dado que essa restrição é ofensiva a mulheres e homens, e gera atrasos inenarráveis à sociedade. A outra história que deve ser contada, como aponta Rich, tem mais a ver com uma história totalizante do que com uma história das mulheres. Nesse ponto, as ideias de Rich parecem consoar com as da crítica Nélida Bonaccorsi, nas palavras desta última:

Desde logo, a imagem de um periodo histórico, de uma formação-social, será mais rica e mais completa, na medida que as mulheres, em suas qualidades de atores sociais, estão presentes, participam e compõem parte dessa realidade. A proposta não é realizar uma história das mulheres, simplesmente, em sua vida cotidiana, no 'interior' - essa história que com tanta frequência só se descreve como a história da condição das mulheres -, mas sim centralizar os interesses no que muda, no que dá pertinência a uma história das mulheres, onde elas se revelam não como figuras, mas como sujeitos da história. Só quando as mulheres tiverem ocupado o status que as corresponde na história, que se poderá começar a elaborar uma história que contemple ambos os sexos de forma globalizante, totalizadora (BONACCORSI, 1996, p. 21, tradução nossa). ${ }^{7}$

A partir das reivindicações de Rich e Bonaccorsi, o presente trabalho reitera o lugar de Maria do Carmo Ferreira na história da poesia concreta brasileira, isso porque, é uma grande injustiça responsabilizar a própria poeta pelo seu desaparecimento histórico, quando há uma conjuntura social especializada em invisibilizar as mulheres. No caso dela, é pertinente pensar ainda os cercos impostos no campo da poesia, pois, além dos tolhimentos sociais, como por exemplo, a negligência das mulheres diante de entrevistas, reportagens e oportunidades de publicação; existe no meio literário uma ideia carregada de preconceitos em relação à poesia feita por mulheres.

Em ensaios críticos, a poeta Ana Cristina Cesar (2016, p. 258) chama atenção para os recortes que localizam, "com alguma precisão, o exato espaço e tom em que a mulher (agora moderna) deve fazer literatura". Ana C. sugere:

Faça uma enquete tipo Globo Repórter. Saia à rua e pergunte aos pedestres: o que é poesia: o que é mulher; e mulher fazendo poesia, fala de quê. As respostas vão configurar o senso comum do poético e do feminino. Surgirão algumas imagens que se convencionou chamar da natureza e considerar belas. O cancioneiro popular. Perfume, pérola, flor, madrugada, mar, estrela, orvalho, pólen, coração. Tépido, macio, sensivel. E em aparente contradição: inatingivel, inefável, profundo. A velha contradição que os românticos não conseguiram resolver. Mulher é inatingivel e sensual ao mesmo tempo. Carne e luz. Poesia também. O poético e o feminino se identificam (CESAR, 2016, p. 250).

\footnotetext{
6 Do original: Both the victimization and the anger experienced by women are real, and have real sources, everywhere in the environment, built into society. They must go on being tapped and explored by poets, among others. We can neither deny them, nor can we rest there. They are our birth-pains, and we are bearing ourselves. We would be failing each other as writers and as women, if we neglected or denied what is negative, [...]. We all know that there is another story to be told.

7 Do original: Desde luego, la imagen de un periodo histórico, de una formación-social será más rica y más completa, en la medida que las mujeres en su calidad de actores sociales, estén presentes, participen y conformen parte de esa realidad. La propuesta es no realizar una historia de las mujeres simplemente en su vida cotidiana, en el "adentro", -esa historia que' con tanta frecuencia suele describirse como historia de la condición de las mujeres- sino centrar el interés en lo que cambia, en lo que otorga pertinencia a una historia de las mujeres, alli donde éstas se revelan no como figurantes, sino como sujetos de la historia. Recién cuando las mujeres hayan ocupado en la historia el status que le corresponde podrá comenzar a elaborarse una historia contemplando a ambos sexos en forma globalizante, totalizadora.
} 
A despeito do perigo eminente, o que não faltam são cercos que definem o lugar da poesia dita feminina - não de mulher -, que, de um certo modo, conversa com a mística feminina proposta por Friedan. Nessa medida, as imagens frivolas do perfume, pérola, orvalho e pólen, carregam caprichos românticos, que, novamente, encarceram as mulheres entre os vértices da mística: casa, marido e filhos. Consequentemente, parece que os únicos temas permitidos às mulheres poetas são aqueles relacionados ao universo da futilidade e do amor piegas. Ana C. (2016, p. 253) complementa o raciocinio descrevendo que, "no fundo, a ideia de procurar uma poesia feminina é uma ideia de homens, a manifestação, em alguns críticos, de um complexo de superioridade masculina", ou seja, a mesma sociedade que tolhe os espaços com atitudes cotidianas, também rebaixa a importância poética das mulheres com base em uma imagem feminina, que é muito bem desenhada, lapidada e polida.

Aqui, além de sublinhar os elementos concretos nos poemas de Maria do Carmo, relatou-se como os versos matam a mistica feminina, permitindo, assim, que a poeta coma o mundo a mordidas e ocupe o seu lugar na história.

\section{Vamos aos poemas...}

Publicado pela primeira vez em 1992, na revista de arte Ímã número 5 (por coincidência, o último número produzido), o poema "As parcas" é rico em expedientes joyceanos e mallarmeanos, que exploram a multiplicidade das palavras (cito o poema completo).

Ela me odeia. -Quem?

A garra da mão morta.

O fantasma sem rosto.

O fetiche-fantoche.

A que me sevicia.

A gira que anda à roda.

A que me dobra e lança

uma navalha solta.

A que jamais se abranda

A ventriloqua. A louca.

A de azul-claro. A rosa.

A funérea de roupas.

A negra. A mais velhaca.

A górgona. A medusa.
A furibunda. A apócrifa.

A só indigência e astúcia, filha de Pênia e Poros.

Midas de merda. A múmia.

A vera efígie beócia.

A imutável figura

junto à Mansão das Horas.

Via-me ver-me: a cínica.

A doida. A douta. A doxa.

A Adèle $\mathrm{H}$. das clínicas.

As Noras e Anas óbvias.

A invídia que me inveja.

O colofão da dúvida.

Lêmure-lâmia. A lésbica.

A sinistra. A destruda.

O gancho. A mão da angústia.

A bisca. A bruaca. A tralha.

A egesta. A harpia. A fúria.

O súcubo. A mãe-drácula.

A cimentada em mim.

A caipira. A caipora

O furo. A cicatriz.

La cuna da memória.

A antipoda. A dismútua:

não ata nem desata.

A come-e-dorme. A muda.

A que me abana o rabo.

A que me rosna e ronca.

A que me morde e sopra.

A histérica. A histriônica.

A que não tem luz própria.

A que avança: a gradiva.

A que recua: a tântala.

A entiquica. A distíquica.

O golem: a que desmonta.

A outra: a conta-gotas.

A que afinal assoma

no fim do último ato.

A triplice má dona.

A que empunha a tesoura.

A que intervém: mão única.

A que intercepta e corta

(Cloto. Láquesis. Átropos.)

o fio... da fortuna.

(FERREIRA, [2000]).

Sem utilizar a palavra mulher e articulando um caminho de palavras-metáforas, o poema parece buscar dar conta das multiplicidades da estranha discrepância que existe entre ser mulher e a figura feminina. Com isso em mente, a palavra "parcas" do título pode ser entendida em duas definições, ela pode tanto fazer referência ao 
mito grego da tríade de deusas (Cloto, Láquesis e Átropos) que determinam e dominam o fio da vida humana, quanto pode assumir o significado mais simples do casaco de pele, isto porque essa veste pode ser feita da pele das deusas que fiam a vida. A mulher não é, justamente, aquela capaz de gestar a vida? No entanto, a parca de pele divina oferece mais desvantagens que vantagens, com roupagens angelicais, suaves e puras, as mulheres zelam pelas necessidades e conforto dos homens. Existe, assim, algo na "parca" que as cercam e limitam à figura da mistica feminina e as ligam fortemente com a condição da maternidade.

Em "As parcas", pode-se sugerir que a imagem sagrada se transforma "no fantasma da mistica feminina" (FRIEDAN, 1971, p. 90), que é dada pela palavra "fantasma". Para Friedan (1971, p. 90), a mistica encoraja a mulher "a viver de pés atados a velha imagem da gloriosa feminilidade", no poema ela é chamada de "fetiche-fantoche", pois as mulheres da mistica não precisam estudar, produzir ou ter opinião, precisam ser belas e agradáveis, como fetiches ou melhor fantoches e ventriloquos, que repetem movimentos e falas sociais sem pensá-los criticamente.

Seu sonho único era ser esposa e mãe perfeita. Sua mais alta ambição, ter cinco filhos e uma bonita casa. Sua única luta, conquistar e prender o marido. Não pensavam nos problemas do mundo para além das paredes do lar e, felizes em seu papel de mulher, desejavam que os homens tomassem as decisões mais importantes, e escreviam, orgulhosas, na ficha do recenseamento: "Ocupação: dona de casa" (FRIEDAN, 1971, p. 20).

Esta "imutável figura" agarra e aprisiona a mulher durante séculos. Virginia Woolf ainda completa a imagem mística feminina, lembrando que a figura angelical está sempre pronta para se sacrificar pelo lar.

Sacrificava-se todos os dias. Se o almoço era frango, ela ficava com o pé; se havia ar encanado, era ali que ia se sentar - em suma, seu feitio era nunca ter opinião ou vontade própria, e preferia sempre concordar com as opiniões e vontades dos outros. E acima de tudo - nem preciso dizer - ela era pura. Sua pureza era tida como sua maior beleza - enrubescer era seu grande encanto (WOOLF, 2020, p. 12).

Quando não eram anjos dos lares, as mulheres eram automaticamente o oposto, maléficas e cheias de sortilégios, "a bisca" ou "a bruaca", que é "só indigência e astúcia", ou a própria "medusa", górgona de "dentes enormes como os do javali, garras de bronze e cabelos de serpentes" (BULFINCH, 1965, p. 137). A "efígie beócia", ou a parca que envolve a furiosa divindade grega, que, no poema, tem a ação desencadeada por jogos paronomásicos, partindo da formação "A que me..." (A que me sevicia. [...] A que me dobra e lança [...] A invidia que me inveja [...] A que me abana o rabo. I A que me rosna e ronca. / A que me morde e sopra.). A figura que se opõe a angélica é marcada pelo divórcio, pela angústia invídia que desagua e ecoa a inveja e tem em si a contradição da fúria e da piedade, pois, ao fim, assopra as feridas abertas por suas lanças e dentes.

A despeito da maternidade angelical ou astúcia demoniaca, a capacidade mental da mulher é sempre posta em dúvida, não precisa muito para chamá-las "louca" e "doida", além de existir toda uma teoria freudiana para delineá-las "histéricas". No poema, há uma rima interessante entre "histérica" e "histriônica", esta última é definida como um transtorno de personalidade caracterizado pela necessidade excessiva de chamar atenção para si, assim, a histeria transforma-se de um distúrbio emocional em uma patologia sofisticada, ambas tendem fixar as mulheres num lugar de instabilidade psicológica, consequentemente, delineando-as como o ser "que não tem luz própria".

Para resumir a ideia, o eu lírico traz à tona o cabalistico golem, figura mistica que nasce de um sonho, renasce como um palimpsesto e possui um destino irreal. Borges dedica à criatura o poema "El golem"8 e o conto "Ruinas circulares"; cita-se um trecho do poema para exemplificar:

\footnotetext{
O simulacro alçou os sonolentos

Olhos e entreviu formas e cores

Sem entender, perdidos em rumores,

E ensaiou temerosos movimentos.
}

\footnotetext{
8 Em entrevista em agosto de 1971, Borges revela: "Depois li um livro de Trachtenberg sobre superstições judaicas onde se fala do golem - ao qual dediquei um poema, possivelmente o melhor poema que escrevi" (SOSNOWSKI, 1991, p. 17).
} 
Gradualmente se viu (tal como nós) Aprisionado na rede sonora

De Antes, Depois, Ontem, Enquanto, Agora, Direita, Esquerda, Eu, Tu, Eles, Vós

(BORGES, 2013, tradução Augusto de Campos). ${ }^{9}$

Como o golem, que gradualmente vê (tal como nós) a realidade: das cores, sonoras e do agora. As mulheres, em "As parcas", despertam para um mundo além da imagem que é sonhada para ela, isto é, a figura da mistica feminina, que a ata como efígie, desenhando e lapidando aquilo que ela deveria ser, enquanto no seu interior definham sonhos e vontades. Como desabafa o narrador de Borges (1999, p. 28-29): "não ser um homem, ser a projeção do sonho de outro homem, que humilhação incomparável, que vertigem!", da mesma maneira, a mística pode ser entendida, como um sonho do homem sobre a mulher. Nos versos finais de Maria do Carmo, existe um tom de desaprisionamento: a "tesoura" "intercepta e corta" um fio que, aqui, se refere mais às amarras sociais da mística, do que à continuidade da vida. O que o eu lírico faz agora é apenas da sua própria conta e não está mais no poema.

Além do intertexto com a mitologia grega e judaica, e os diálogos com Borges, é interessante notar ainda que, no poema, as palavras "fetiche-fantoche", "mãe-drácula" e "come-e-dorme", são neologismos construídos ao estilo joyceano. Sugere-se também que a pontuação tem algo de mallarmeano, pois determina uma sintaxe especial firmada na subdivisão da ideia, que trata o poema quase como uma partitura de música, isso porque, como não há estrofes, a pontuação, junto com a quebra dos versos, é responsável por dar o tempo das pausas do texto. É inegável, portanto, a presença do paideuma concreto na produção de Maria do Carmo, consolidando a ideia de que a poeta tinha um lugar na poesia concreta para além do flerte, pois ele continua sendo expresso na sua poética.

"De mim pra mins" é outra criação de Maria do Carmo que carrega essas peculiaridades concretas. Publicado na revista Germina: revista de literatura \& arte, em 2006, o poema é datado de novembro de 2003 e foi escrito em Niterói, onde Maria do Carmo ainda reside (cito o poema completo).

Que eu saiba, não vivi.

E é como se

(quantas vezes me ocorra

perscrutar-me).

As potencial'idades

que perdi...

Delas não sucumbi?

É como se.

Saudade, à falta de melhor palavra,

desde caminhos que

não me elegi.

E, se me houveram,

de outros so... cor...

ri-me.

Dentre os,

ainda que viva,

amor' fino?

É como se.

Como se, não por mim, me decidissem.

E se entre só impostores

viessem a ser

a assás viagem soída

até aqui.

via trans'verso três-

loucado...

É como se.

Não pus ao menos os pingos nos is.

E nem de um iota dispensou-me a vida.

Morro de idéias,

d' id-ios' sincrasias.

De outrora, nost'algia?

É como se.

Não sã arrufos de invejo'so alheio.

Por opção, nada me apete'cia.

Arei, semeei meu próprio mau canteiro. Deu cizânia. Sem tri-

go...

É como se.

Como se tudo ou nada viesse a furo 
sob a assistente chu-

va'de... Finados.

Morrendo lentamente,

alma crestada,

não deserta... de mim?

É como se. (FERREIRA, 2003).

O poema é composto por seis estrofes e uma coda, o eu lírico em primeira pessoa conta sobre sua subjetividade. O título, "De mim pra mins", tem um tom de bilhete ou de diário, escrito para si mesmo, como um lembrete para os vocês-futuros, que se intendem no plural dado a imprevisibilidade do destino. A coda, "é como se", endossa essa miragem ao futuro, perpassando todo o texto como um refrão ou um eco de uma quase-vida, cuja incompletude imbrica-se na linguagem. "Como se" a vida fosse um quase, ela está constantemente prestes a começar, mas nunca começa de fato, ao contrário, é restrita às suas potencialidades perdidas, existe aí um sentimento saudosista por algo que nem sequer existiu, algo menor que um sonho, algo que tende ao fechado, como as letras $\langle e\rangle$ e $\langle 0\rangle$, únicas vogais da coda.

Este futuro fechado e restrito parece retomar aspectos da mística feminina. Nas palavras de Friedan, elas:

Ficavam sabendo que a mulher verdadeiramente feminina não deseja seguir carreira, obter educação mais aprofundada, lutar por direitos políticos e pela independência e oportunidades que as antigas feministas pleiteavam. Algumas, entre quarenta e cinquenta anos, lembravam-se ainda de terem renunciado com pesar a esses sonhos, mas a maioria já nem pensava neles (FRIEDAN, 1971, p. 17-18).

Ela relata que nos Estados Unidos ocorreu um fenômeno na década de 1950, que ia na contramão das lutas feministas por acesso à educação para as mulheres, segundo a ativista, "as moças iam à universidade para arranjar marido. Em meados da década, 60\% abandonaram a faculdade para casar, ou temendo que o excesso de cultura fosse um obstáculo ao casamento" (FRIEDAN,
1971, p. 18). Havia um outro universo voltado para o marido, casa e, sobretudo, maternidade, que chamava pelas mulheres. Não havia incentivo social para que estudassem e seguissem carreira, ao invés disso, os cercos invisiveis embaçavam esse perfil com a perversão da imagem da mulher que se afasta da mística. Retidas ao lar, em uma quase-vida que esgarça os dias, elas gritam ajuda, um grito engasgado de "so... cor.../ ri-me.", como prefere Maria do Carmo.

Entretanto, nem sabiam ao menos pôr nome no problema pelo qual gritavam, quando Friedan (1971, p. 21) medita nas "palavras usadas pelas mulheres ao tentar descrevê-lo", recorda que "às vezes diziam: 'Estou me sentindo vazia... incompleta'. Ou então: 'Tenho a impressão de não existir'", esse sentimento sem nome aparece nos versos: "Como se, não por mim,/ me decidissem.", e o eu lírico continua sua reclamação: "Não pus ao menos os/ pingos nos is." e "dis-/pensou-me a vida.", há aqui uma tentativa de reinvindicação de local de reconhecimento profissional. Ainda que o eu lírico semeei o próprio canteiro, os frutos são "cizânia", isto é, o joio (maléfico resíduo) sem o trigo (aquilo que realmente alimenta). O poema relata, dessa forma, sobre o aparente furo da história, por onde escoam a colheita, desejos e sonhos do eu lírico.

"Sob a assistente chu-/va'de... Finados" emerge a referência à crônica "A morte devagar", ${ }^{10}$ de Martha Medeiros, que retoma também o verso "pingos nos is", do poema de Maria do Carmo. Cito um trecho da crônica:

Morre lentamente quem evita uma paixão, quem prefere o preto no branco e os pingos nos is a um turbilhão de emoções indomáveis, justamente as que resgatam brilho nos olhos, sorrisos e soluços, coração aos tropeços, sentimentos (MEDEIROS, 2000, p. 15).

Em "De mim pra mins", sugere-se que o eu lírico morre lentamente do mal sem nome, observado por Friedan, que advém do isolamento em cercos invisiveis socialmente construidos pelo patriarcado. Dessa maneira, pode-se depreender uma

10 A história da crônica é curiosa, publicada em 2000, no jornal Zero Hora, de Porto Alegre, foi, por muito tempo, considerada como produção de Pablo Neruda (a reportagem sobre o assunto pode ser consultada no jornal O Estado de São Paulo em 12 jan. 2009 ). Desse modo, o causo que envolve a crônica também se confunde com o problema do reconhecimento da criação poética profissional das mulheres. 
relação íntima entre o eu lírico e a consciência da mistica feminina, que o restringe e combusta suas vontades. O poema encerra-se com a coda "é como se", perpetuando a quase-vida, pois entende-se aqui que a desinvisibilização dos cercos da mística não garante qualquer espaço histórico ou reconhecimento profissional às mulheres. Em outras palavras, é um poema duro, que expõe a subjetividade do eu lírico de uma forma crua, até porque, recuperando novamente o título, não são necessários rodeios quando se escreve para si.

É interessante notar que os recursos estéticos concretos continuam presentes no poema, por exemplo, na construção das palavras "potencial'idades", "amor' fino", "trans'verso", "d' id-ios' sincrasias", "nost'algia", "in-/vejo'so" e "chu-/va'de... Finados", que utilizam um método ao estilo de cummings, cuja sintaxe explora foneticamente as possibilidades de significação. O recurso verbivocovisual joyceano também se manifesta no poema, está tanto nos aspectos melopéicos, ligados à sonoridade fonética das palavras, quanto na visualidade do texto, na qual os enjambements têm participação fundamental, pois contribuem para que os versos assumam uma forma particular.

Joyce, Mallarmé e cummings são poetas ligados ao paideuma da poesia concreta, mas também são nomes que emergem na análise atenta dos poemas de Maria do Carmo. Além de compartilhar o paideuma com os concretos, a poeta realiza, até a data de finalização deste artigo, atividade de tradução e de criação poética sistemática, que em tudo condiz com os concretos, tendo inclusive publicado entre eles na revista Invenção 5. Repensando o contexto da década de 1960, os motivos que levam ao desaparecimento da figura de Maria do Carmo parecem estar fortemente ligados ao seu gênero e às posições profissionais que são circunscritas a ele. Existe, ainda hoje, uma dominação falocêntrica na articulação dos saberes e na escolha de quem entra ou não na história oficial, com evidente predileção dos seus pares. Nesse cenário, as mulheres são deixadas de lado, a elas é oferecida a mística feminina no estilo autoritário de "ama-a ou deixe-a", isto é, ou a mulher se adapta ao feminino ou nem sequer é considerada mulher, mas antes tida como um ser maléfico e imoral.

Portanto, se a exposição e o rompimento com a mistica feminina nos poemas "As parcas" e "De mim para mins" não foram suficientes para incluir Maria do Carmo na história da poesia concreta, talvez seja mais pela força dos cercos que tolhem as mulheres do que pela qualidade de seus poemas. Lembrando que a invisibilização não é operada por uma ou duas pessoas, mas de forma estrutural; os cercos são aplicados de forma sistemática e mascarados por um "querer bem" ou, ainda pior, responsabilizando a própria mulher pelo seu desaparecimento histórico, como se partisse apenas da vontade dela e não de uma conjuntura social. Aqui, além de reconhecer os aspectos concretos nos poemas, verificou-se que os versos reconhecem e tentam transcender a mística feminina. Este artigo dá força a essa tentativa, concedendo à Maria do Carmo Ferreira o lugar na história da poesia brasileira que é seu por direito.

\section{Referências}

AGUILAR, Gonzalo. Poesia Concreta Brasileira: As vanguardas na encruzilhada modernista. São Paulo: Editora da Universidade de São Paulo, 2005.

BONACCORSI, Nélida. Repensar la historia de las mujeres. Universidad Nacional de Luján, 1996. v. 1.

BORGES, Jorge Luis. Ruinas circulares. In: BORGES, Jorge Luis. Ficções. São Paulo: Editora Companhia das Letras, 1999. p. 25-28.

BORGES, Jorge Luis. El Golem. In: CAMPOS, Augusto. Quase Borges: 20 transpoemas e uma entrevista. São Paulo: Terracota, 2013

BOURDIEU, Pierre. A incorporação da dominação. In: BOURDIEU, Pierre. A dominação masculina. 11. ed. São Paulo: Bertrad Brasil, 2012. p. 32-98

BULFINCH, Thomas. As greias e as górgonas - Perseu - Medusa - Atlas - Andrômeda. In: BULFINCH, Thomas. O livro de ouro da mitologia. Rio de Janeiro: Editora Tecnoprint, 1965. cap. 15. p. 135-142.

CAMPOS, Augusto de. Poetamenos. In: CAMPOS, Augusto de. PIGNATARI, Décio CAMPOS, Haroldo de. Teoria da poesia concreta. 4. ed. São Paulo: Ateliê Editorial, 2006. p. 29-30

CAMPOS, Augusto de. Poesia concreta. In: CAMPOS, Augusto de. PIGNATARI, Décio CAMPOS, Haroldo de. Teoria da poesia concreta. 4. ed. São Paulo: Ateliê Editorial, 2006. p. 55-62. 
CAMPOS, Haroldo de. Olho por olho a olho nu. In: CAMPOS, Augusto de. PIGNATARI, Décio CAMPOS, Haroldo de. Teoria da poesia concreta. 4. ed. São Paulo: Ateliê Editorial, 2006. p. 73-76.

CESAR, Ana Cristina. Literatura e mulher: essa palavra de luxo. In: CESAR, Ana Cristina. Crítica e tradução. São Paulo: Companhia das letras, 2016. p. 249-259.

ESTADÃO. Falso poema atribuido a Neruda é da brasileira Martha Medeiros. O Estado de São Paulo, São Paulo, 12 jan. 2009. Disponivel em: https://cultura. estadao.com.br/noticias/geral,falso-poema-atribuido-a-neruda-e-da-brasileira-martha-medeiros.306181. Acesso em: 1 jan. 2021.

FERREIRA, Maria do Carmo. As parcas. In: Jornal de poesia. [S. I.], ago. 2000. Disponivel em: http://WwW. jornaldepoesia.jor.br/mcferreira.html\#as\%20prcas. Acesso em: 11 jan. 2021.

FERREIRA, Maria do Carmo. Carmina Bu(saga)rana. Suplemento Literário de Minas Gerais, Belo Horizonte, edição especial, p. 31-32, 2013. Disponivel em: http:// www.bibliotecapublica.mg.gov.br/index.php/pt-br/ suplemento-litelario/edicoes-suplemento-literarios/ edicoes-especiais-1/90--90/file. Acesso em: 11 jan. 2021

FERREIRA, Maria do Carmo. De mim para mins. Germina: revista de literatura \& arte - Especial: Minas, de passagem, [S. I.], v. 2, n. 3, 2006. Disponivel em: https://WwW. germinaliteratura.com.br/maria_do_carmo_ferreira. htm. Acesso em: 11 jan. 2021.

FRIEDAN, Betty. A heroina doméstica. In: FRIEDAN, Betty. Mistica feminina. Rio de Janeiro: Editora Vozes Limitada, 1971. cap. 3. p. 17-31.

FRIEDAN, Betty. A vibrante jornada. In: FRIEDAN, Betty. Mistica feminina. Rio de Janeiro: Editora Vozes Limitada, 1971. cap 5. p. 71-90.

FRIEDAN, Betty. O problema sem nome. In: FRIEDAN, Betty. Mistica feminina. Rio de Janeiro: Editora Vozes Limitada, 1971. cap. 1. p. 32-61.

MEDEIROS, Martha. A morte devagar. Zero Hora, Porto Alegre, 1 nov, 2000, p.15.

MAIOLINO, Anna Maria. Museu vivo: Ana Maria Maiolino (Parte 1). Sesc TV, 2015. Disponivel em: https://Www.youtube.com/watch?V=4ZJ1bF1p8Yk. Acesso em: 21 jan. 2021.

PAROS, Felipe Martins. Seguindo o Meretrilho: sobre um poema de Maria do Carmo Ferreira. Revista Gama: estudos Artísticos, Lisboa, n. 7. v. 13, p. 36-43, 2019.

$\mathrm{RICH}$, Adrienne. When we dead awaken: Writing as re-vision. College English, [S. I.], v. 34, n. 1, p. 18-30, 1972.

SOSNOWSKI, Saúl. Borges e a Cabala. São Paulo: Editora Perspectiva, 1991. $96 \mathrm{p}$.

WOOLF, Virginia. Profissões para mulheres. In: WOOLF, Virginia. Profissões para mulheres e outros artigos feministas. Porto Alegre: L\&PM, 2020. p. 9-19.

\section{Monalisa Medrado Bomfim}

Mestre e doutoranda em Estudos de Literatura, Departamento de Letras, Universidade Federal de São Carlos (UFSCar), em São Carlos, SP, Brasil.

\section{Endereço para correspondência}

Monalisa Medrado Bomfim

Universidade Federal de São Carlos

Departamento de Letras

Rod. Washington Luiz km 235

Jardim Guanabara, 13565-905

São Carlos, SP, Brasil

Os textos deste artigo foram revisados pela Poá Comunicação e submetidos para validação da autora antes da publicação. 